\title{
The Direct Sandwich Composite Molding (D-SCM) Process: Sandwich Manufacturing and Characterization
}

\author{
Felix Behnisch ${ }^{1, * \mathbb{D}}$, Jonathan Brütsch ${ }^{1}$, Henrik O. Werner ${ }^{2,3}$ and Frank Henning ${ }^{1,3}$ \\ 1 Fraunhofer-Institute for Chemical Technology ICT, Joseph-von-Fraunhofer Str. 7, 76327 Pfinztal, Germany; \\ jonathan.bruetsch@gmail.com (J.B.); frank.henning@ict.fraunhofer.de (F.H.) \\ 2 Institute for Applied Materials-Materials Science and Engineering (IAM-WK), \\ Karlsruhe Institute of Technology (KIT), 76131 Karlsruhe, Germany; henrik.werner@kit.edu \\ 3 Institute of Vehicle System Technology (FAST), Karlsruhe Institute of Technology (KIT), \\ 76131 Karlsruhe, Germany \\ * Correspondence: felix.behnisch@ict.fraunhofer.de
}

Citation: Behnisch, F.; Brütsch, J.; Werner, H.O.; Henning, F. The Direct Sandwich Composite Molding (D-SCM) Process: Sandwich

Manufacturing and Characterization J. Compos. Sci. 2022, 6, 81.

https://doi.org/10.3390/jcs6030081

Academic Editor: Stelios K.

Georgantzinos

Received: 9 February 2022

Accepted: 28 February 2022

Published: 5 March 2022

Publisher's Note: MDPI stays neutral with regard to jurisdictional claims in published maps and institutional affiliations.

Copyright: (C) 2022 by the authors. Licensee MDPI, Basel, Switzerland. This article is an open access article distributed under the terms and conditions of the Creative Commons Attribution (CC BY) license (https:// creativecommons.org/licenses/by/ $4.0 /)$

\begin{abstract}
Sandwich structures benefit from the geometrical stiffening effect due to their high crosssectional area moment of inertia. Transferred to carbon fiber-reinforced plastic (CFRP) components, the needed amount of carbon fiber (CF) material can be reduced and with it the $\mathrm{CO}_{2}$ footprint. The combination of a light foam core with continuous fiber-reinforced face sheets is a suitable material combination for lightweight design. Traditionally, CFRP sandwich structures with a foam core are manufactured in a two-step process by combining a prefabricated foam core with fiber-reinforced face sheets. However, in addition to the reduction in the used CFRP material, manufacturing processes with a high efficiency are needed. The objective of this paper is the sandwich manufacturing and characterization by using the Direct Sandwich Composite Molding (D-SCM) process for the onestep production of CFRP sandwich structures. The D-SCM process utilizes the resulting foaming pressure during the reactive polyurethane (PUR) foam system expansion for the impregnation of the CF-reinforced face sheets. The results of this work show that the production of sandwich structures with the novel D-SCM process strategy is feasible in one single manufacturing step and achieves good impregnation qualities. The foam density and morphology significantly influence the core shear properties and thus the component behavior under a bending load.
\end{abstract}

Keywords: sandwich structures; lightweight structures; advanced composites; polyurethane foam

\section{Introduction}

Existing legal frameworks and social pressure set the requirements for material and production process developments. The environmental impact by harmful emissions is increasingly monitored, from manufacture to disposal (life cycle assessment). Carbon fiber-reinforced plastic (CFRP) components have to face the challenge of the high resource consumption during material extraction (greenhouse gas impact of $38.9 \mathrm{~kg} \mathrm{CO}$-equivalent per $\mathrm{kg} \mathrm{CF} \mathrm{[1])} \mathrm{and} \mathrm{component} \mathrm{manufacture} \mathrm{counteracting} \mathrm{the} \mathrm{weight} \mathrm{and} \mathrm{emission} \mathrm{savings}$ they offer during the use phase. Thus, the development focus must not be exclusively on mechanical performance and cycle times. The environmental impact of CFRP components from the beginning of the product life cycle must be reduced to improve the overall balance of the component during its whole life cycle compared to conventional materials.

One strategy for achieving this is to use a sandwich design for large and flat components. The geometric stiffening effect by increasing the cross-sectional area moment of inertia allows the reduction in the reinforcing carbon fiber material and thus the $\mathrm{CO}_{2}$ footprint for the components. A suitable combination for lightweight design is, for example, the use of continuous fiber-reinforced face sheets with a light foam core [2-5].

In addition to the reduction in CFRP material, more resource-efficient manufacturing processes are needed. CFRP sandwich structures with a foam core are manufactured by 
combining a prefabricated foam core with fiber-reinforced face sheets in a press process. For the face sheets, either pre-impregnated materials (so-called prepregs) can be used, or they can be in situ impregnated during the component manufacturing process. Thus, at least a two-step process is needed since the pressure-sensitive foam core must be manufactured within a previous production step [6-8].

A processing strategy for utilizing the internal pressure generated by a foam core has already been used by $\mathrm{M}$. Ware for the manufacturing of composite sandwich structures within the Thermal Expansion RTM (TERTM) process [9]. A polyurethane (PUR) or polyimide (PI) foam core, combined with dry fabric reinforcing material, is placed in a cold cavity and the resin system is injected. A thermal expansion of the foam core is induced by increasing the mold temperature. The resulting pressure on the infiltrated face sheets improves their impregnation $[9,10]$. An alternative strategy by using foamable films in-between two pre-impregnated face sheets is proposed by Burr et al. in a DOW Global Technologies patent from 2014 for epoxy-based thermosets [11] and by Beukers et al. for thermoplastic polymers [12].

A one-step process strategy is introduced by Hopmann et al., using a syntactic, epoxybased foam system [13]. Hollow polymeric microspheres, loaded with a low-boiling liquid, are used as a blowing agent. The expansion of the blowing particles is induced at rising temperatures due to the heated cavity as the polymeric microsphere shell becomes flexible and the transition of the low-boiling liquid into the gas phase leads to a volume increase. Glass fiber textile reinforcements serve as filters and prevent the microspheres from penetrating the sandwich face sheets. The fabric impregnation is realized by the expansion pressure of the blowing particles, which forces the matrix system into the face sheets. After the curing of the matrix material, the solid polymer network fixates the expanded hollow spheres that remain as pores in the syntactic foam material [13].

Weißenborn et al. introduced another one-step manufacturing strategy by using the expansion reaction of foamable PUR in a closed cavity [14]. Both the foam core and the matrix system for the textile reinforcement of the sandwich face sheets are realized by one single reactive PUR foam system. By manipulating the pressure conditions during the process, the pore content in the face sheets can be influenced. A roving impregnation of $84 \%$ and thus a pore volume of $16 \%$ were achieved at $770 \mathrm{~kg} / \mathrm{m}^{3}$ foam density $[14,15]$.

The one-step sandwich manufacturing method introduced by Hopmann et al. is based on two independent PUR material systems for the foam core and the face sheet impregnation [16]. The face sheet textile reinforcement is wetted by a non-foamable PUR material outside the mold and vacuum supports the pre-impregnation process. Combined with the reactive PUR foam material in the heated cavity, the temperature-induced expansion reaction of the foam system leads to an internal force that presses the face sheets against the mold wall during curing. The investigations showed that the penetration of foam pores into the face sheets cannot be prevented even if the vacuum-assisted wetting of the fiber structure is almost optimal [16,17].

Studies conducted by Hopmann et al. $[16,17]$ and Weißenborn et al. $[14,15]$ showed an uncontrolled penetration of foam pores into the face sheets that lower the mechanical performance. Furthermore, relatively high foam densities (e.g., $770 \mathrm{~kg} / \mathrm{m}^{3}$ [14,15]) are necessary for sandwich manufacturing, which decreases the potential of being light weight. This leads to the need for a more efficient and robust one-step manufacturing technology for a CFRP sandwich structure production. This paper contributes to the development of a one-step manufacturing method for sandwich structures by introducing and investigating the novel Direct Sandwich Composite Molding (D-SCM) process. The focus of this manufacturing strategy is on avoiding foam pore penetration into the face sheets and on achieving low foam core densities. The objectives of this paper are to prove the feasibility of the D-SCM production method and to characterize the achievable sandwich properties in terms of fiber volume content and mechanical behavior under a three-point bending load. 


\section{The Direct Sandwich Composite Molding (D-SCM) Process Strategy}

The basic idea of the intended processing strategy within this paper is the use of the expansion pressure generated during the PUR foam reaction for the fabric impregnation and consolidation of the face sheets. Two independent material systems for the foam core and the fabric impregnation in the face sheets will be used. A thermoplastic PUR (TPU) film is used as an impermeable layer for separating the face sheet and the reactive foam materials to avoid the uncontrolled face sheet penetration of foam cells. Consequently, different resin types for the face sheets (e.g., use of epoxy-based systems) can be used to improve the process flexibility. Additionally, an optimized polyurethane foam system is used for ensuring a high lightweight potential of the structures by decreasing the necessary foam density and increasing the achievable fiber volume content (FVC) of the sandwich face sheets [18].

The focus of this paper is the realization of a one-step process-the Direct Sandwich Composite Molding (D-SCM) Process-for the manufacturing of CFRP sandwich structures by using an optimized polyurethane foam system [18]. The process strategy is described in Figure 1. The stack of a wetted textile fabric and a TPU film is introduced in the heated cavity (1), an optimized reactive PUR foam system [18] is applied into the mold (2) and a second wetted fabric stack plus TPU film forms the upper face sheet (3). After closing the mold to the final component thickness (4), the chemical reaction of the foam material results in an expansion pressure on the face sheets (5). This internal pressure leads to the impregnation of the textile reinforcement, followed by the consolidation (curing) of the face sheets (6). After curing, the cavity can be opened and the sandwich component demolded (7). The resulting sandwich structures are characterized within a three-point bending analysis.

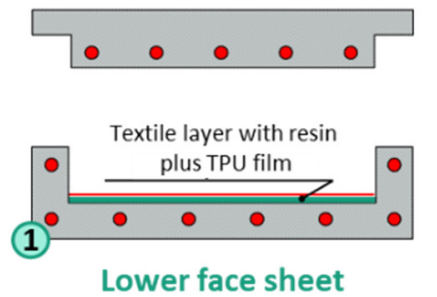

Lower face sheet

put

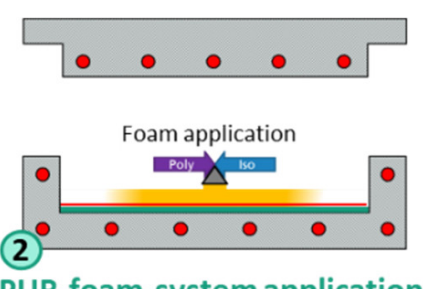

PUR-foam-system application
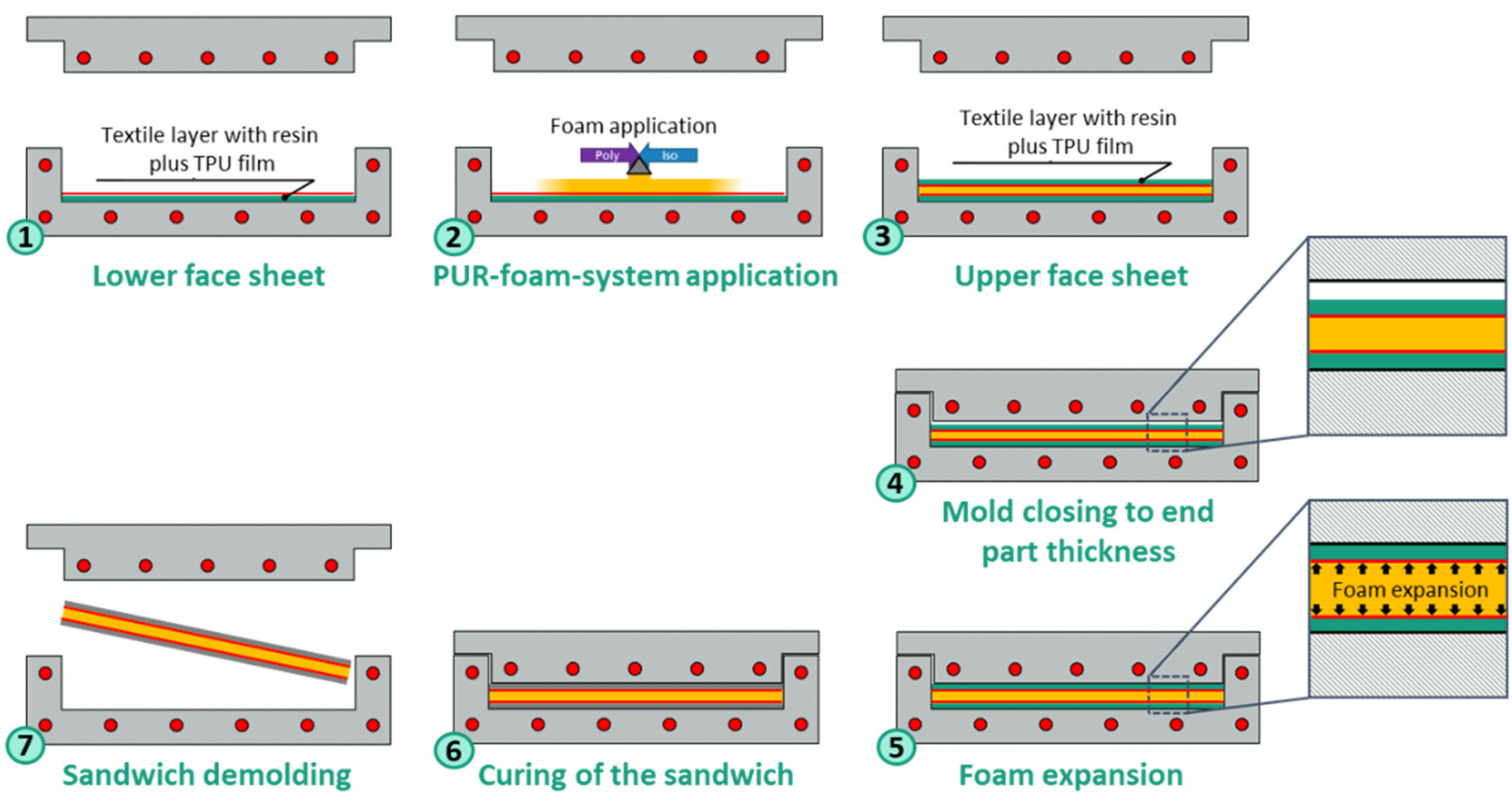

Figure 1. Schematic illustration of the ideal one-step sandwich process: (1) first wetted fabric stack is introduced in the cavity, (2) reactive PUR foam system is applied, (3) second wetted fabric stack is introduced in the cavity, (4) mold is closed to the final component thickness, (5) chemical PUR foam expansion, (6) consolidation (curing) of the face sheets, (7) demolding of the sandwich component.

\section{Materials and Methods}

\subsection{Materials}

The biaxial $\left(0^{\circ} / 90^{\circ}\right), 50 \mathrm{~K}$-based carbon fiber non-crimp fabric (NCF) PX35MD030B127T from Zoltek Corporation was used for the fiber reinforcement of the face sheets. The basic structure of the textile with a basis weight of $304 \mathrm{~g} / \mathrm{m}^{2}$ consists of Panex ${ }^{\circledR} 35$ carbon 
fibers. These were divided proportionally with $150 \mathrm{~g} / \mathrm{m}^{2}$ between the biaxial orientations of the NCF. The carbon fiber filaments were coated with $1.5 \mathrm{wt}$. $\%$ sizing. The material was tricot-stitched with $4 \mathrm{~g} / \mathrm{m}^{2}$ polyester thread [19]. Two layers of the fiber semi-finished product were combined per face sheet to form a symmetrical reinforcement structure of $\left[\left(0^{\circ} / 90^{\circ}\right),\left(90^{\circ} / 0^{\circ}\right)\right]$.

Two thermosetting amine-based epoxy resin systems were used as matrix material for the face sheets. The Epikote ${ }^{\mathrm{TM}}$ TRAC 06170 system from Hexion is a low-viscosity resin system with a pot life of $42 \mathrm{~min} \pm 5$ at $23{ }^{\circ} \mathrm{C}$, developed for liquid impregnation processes [20]. It will be referred to as "Epikote" in the following. The Araldite ${ }^{\circledR}$ LY 3031 system from Huntsman is a fast-curing resin system for automotive mass production and has a pot life of 15 to $25 \mathrm{~min}$ at $23^{\circ} \mathrm{C}$ [21]. The system will be referred to as "Araldite" in the following.

The used PUR foam material for the D-SCM process is based on the two-component system EP 3587/2 from Rühl Puromer GmbH [22]. It consists mainly of polyether polyols and diphenylmethane diisocyanate (MDI). Further additives (e.g., distilled water, catalysts and nucleating agents) are mixed into the polyol component. The PUR system formulation is adjusted to the D-SCM process requirements and includes 3.1 parts of water and 1.1 parts of catalyst related to the polyol quantity [18].

Acmos 36-5238 from Acmos Chemie KG is used as an external mold release agent in the PUR foam manufacturing. For the epoxy resin systems, the semi-permanent solvent-based mold release agent Chemlease ${ }^{\circledR} 255$ from Chem-Trend L.P. was used.

The impermeable barrier layer was formed by a TPU film Type 4110 from Saxonymed $\mathrm{GmbH}$. This is transparent and contains no antiblocking agents. The film had a thickness of $0.1 \mathrm{~mm}$.

\subsection{Experimental Setup}

A circular plate geometry with $150 \mathrm{~mm}$ diameter and adjustable height (shown in Figure 2a ) was used for the one-step manufacturing of CFRP sandwich structures. An electric cylinder (Festo ServoPress YJKP-17-400-AX-SB-5) operated the trial setup and allowed the programming of closing profiles and highly accurate movements of the mold. The schematic cross section of the mold is shown in Figure $2 b$. The resin sealing prevents from leakage of the reactive materials and the vacuum sealing allows an evacuation of the cavity during the process. The mold was water-heated at $80^{\circ} \mathrm{C}$, a pressure sensor (Kistler type 6167A) was installed in the upper mold for online recording of the pressure values and the cavity height can be adjusted via distance rings.

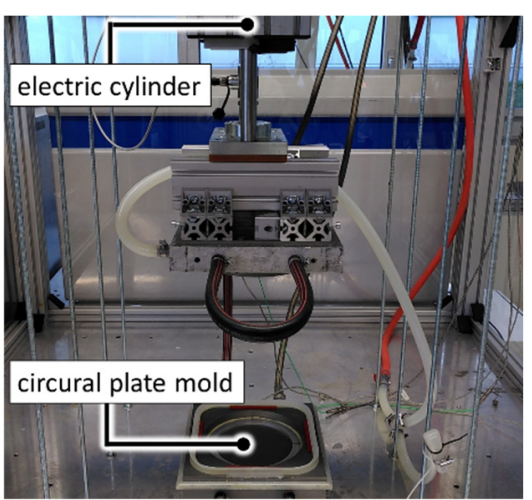

(a)

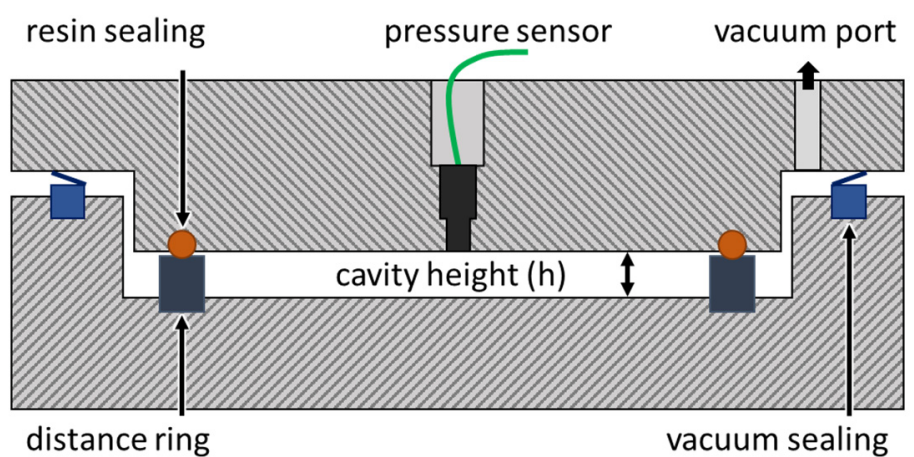

(b)

Figure 2. (a) experimental setup for D-SCM sandwich manufacturing, (b) schematic cross section of the circular plate mold. 


\subsection{Sandwich Specimen Manufacturing}

The one-step sandwich manufacturing follows the general processing steps from Figure 1. The respective matrix material (Epikote or Araldite) was applied on the stack of two biaxial CF fabric layers (148 $\mathrm{mm}$ in diameter) and the impermeable TPU film. The stack was introduced into the heated circular plate mold. Simultaneously, the foam system was manually mixed and applied on the TPU film that covered the wet fabric reinforcement of the lower face sheet. The necessary foam material amount was dependent on the aimed foam density. Table 1 summarizes the manufactured trial configurations. A foam thickness of $4 \mathrm{~mm}$ was aimed for for the core. The second face sheet, consisting of wetted reinforcement fabrics, and the TPU film were placed on top of the reactive foam material. Subsequently, the mold was closed to the final sandwich height of $5.7 \mathrm{~mm}$ in $11 \mathrm{~s}$ according to the programmed closing profile of the electric cylinder. At a mold opening of $3 \mathrm{~mm}$, the vacuum was activated and applied throughout the entire process. From the point at which the resin seal was engaged at $2 \mathrm{~mm}$, the vacuum no longer acted on the sandwich structure. The active vacuum time was $5.5 \mathrm{~s}$. The target face sheet thickness was $0.75 \mathrm{~mm}$, which corresponds to $44.2 \%$ FVC. The curing time was $300 \mathrm{~s}$ for the Araldite system and $600 \mathrm{~s}$ for the Epikote system. The specimens for detailed characterization were prepared by waterjet cutting out of the produced circular sandwich plates.

Table 1. Investigated trial configurations.

\begin{tabular}{ccccc}
\hline Epoxy System & $\begin{array}{c}\text { Foam Core } \\
\text { Density }\end{array}$ & $\begin{array}{c}\text { Foam Core } \\
\text { Material }\end{array}$ & $\begin{array}{c}\text { Face Sheet } \\
\text { Material }\end{array}$ & Curing Time \\
\hline Araldite & $150 \mathrm{~g} / \mathrm{L}$ & $10.6 \mathrm{~g}$ & $9.5 \mathrm{~g}$ & $300 \mathrm{~s}$ \\
Araldite & $200 \mathrm{~g} / \mathrm{L}$ & $14.1 \mathrm{~g}$ & $9.5 \mathrm{~g}$ & $300 \mathrm{~s}$ \\
Araldite & $250 \mathrm{~g} / \mathrm{L}$ & $17.7 \mathrm{~g}$ & $9.5 \mathrm{~g}$ & $300 \mathrm{~s}$ \\
Epikote & $150 \mathrm{~g} / \mathrm{L}$ & $10.6 \mathrm{~g}$ & $9.5 \mathrm{~g}$ & $600 \mathrm{~s}$ \\
Epikote & $200 \mathrm{~g} / \mathrm{L}$ & $14.1 \mathrm{~g}$ & $9.5 \mathrm{~g}$ & $600 \mathrm{~s}$ \\
Epikote & $250 \mathrm{~g} / \mathrm{L}$ & $17.7 \mathrm{~g}$ & $9.5 \mathrm{~g}$ & $600 \mathrm{~s}$ \\
\hline
\end{tabular}

The TPU film provides high adhesion properties to the PUR core and the Epoxy face sheet material. To be able to determine the correct FVC, the face sheets must be produced to be detachable from the foam core. For this purpose, D-SCM trials were carried out and a PTFE film of identical thickness was inserted between the foam system and the face sheets instead of the TPU film. As there was adhesion between the used reactive materials and the PTFE film, this allowed the foam core and face sheets to be separated from each other after the process. The detailed trial configurations for the sandwich processing can be found in Table 1.

\subsection{Characterization Methods}

\subsubsection{Thermogravimetric Analysis of the Face Sheets}

The FVC was determined by a thermogravimetric analysis (TGA). In this characterization method, the polymeric content of the composite is pyrolyzed and the mass of the remaining carbon fibers is determined.

For the TGA, three specimens $\left(22 \times 30 \mathrm{~mm}^{2}\right)$ were cut out of each face sheet by water jet cutting and their density $\rho_{\text {Sample }}$ was determined in a gas pycnometer (PYCNOMATIK ATC from Microtrac Retsch GmbH) according to DIN 66137-2, and their weights $m_{\text {Sample }}$ were measured. The pyrolysis was carried out in a macro TGA of the type TGA701 from Leco Corporation. The test procedure was implemented according to the method of Bücheler et al. [23]:

- Drying of the specimens for $6 \mathrm{~h}$ at $100^{\circ} \mathrm{C}$.

- Pyrolysis of the specimens in nitrogen atmosphere:

Heating rate: $2 \mathrm{~K} / \mathrm{min}$.

Pyrolysis temperature: $430^{\circ} \mathrm{C}$. 
Pyrolysis duration: $20 \mathrm{~h}$.

Subsequently, the mass of the matrix-free fibers $m_{C F}$ was determined. Referring to the investigations of Bücheler et al., the sizing was burned off from the fiber during the pyrolysis process. For the correct calculation of the fiber volume content, the mass of the sizing $m_{\text {sizing }}\left(1.5 \% \cdot m_{C F}\right)$ was again added to the fiber mass. Thus, the combined density $\rho_{C F}$ of the Panex ${ }^{\circledR} 35$ carbon fiber of $1.81 \mathrm{~g} / \mathrm{cm}^{3}$ [19] can be used to determine the fiber volume $V_{C F}$. The fiber volume content was calculated as follows:

$$
F V C=\frac{V_{C F}}{V_{\text {sample }}} \cdot 100 \%=\frac{\left(m_{C F}+m_{\text {sizing }}\right) \cdot \rho_{C F}}{m_{\text {sample }} \cdot \rho_{\text {sample }}} \cdot 100 \%
$$

\subsubsection{Tensile Characterization of the Face Sheets}

The stiffness of the face sheets $E_{F S}$ was determined in a tensile test based on DIN EN ISO 527-1. For this purpose, the face sheets were separated from the core structure and the test specimens $\left(120 \times 15 \mathrm{~mm}^{2}\right)$ with the corresponding fiber orientation of $[0 / 90]_{S}$ were prepared. A small amount of foam residue and the TPU film remained on the tensile specimen. Their influence on the face sheet stiffness was neglected in the following, since the mechanical properties were significantly lower compared to the CFRP specimen (e.g., Young's modulus of the TPU Elastollan ${ }^{\circledR}: 400 \mathrm{MPa}$ at $20{ }^{\circ} \mathrm{C}$ [24]). The tests were carried out on a standard universal testing machine (Hegewald \& Peschke, inspekt 50 table) with a test speed of $1 \mathrm{~mm} / \mathrm{min}$.

\subsubsection{Three-Point Bending Characterization of Sandwich Structure}

The test was performed in accordance with ASTM C393/C393M-16, one of the standard test methods for sandwich characterization $[25,26]$. The 3-point bending test fixture was installed in a Zwick/Roell Z2.5 universal testing machine, shown in Figure 3. The radius of the three supports was $2 \mathrm{~mm}$. In accordance with the standard, an elastomer layer was introduced at the pressure fin (shore hardness: 60; width: $25 \mathrm{~mm}$; thickness: $3 \mathrm{~mm}$ ) for homogenized introduction of the test load into the specimen (dimensions: $\left.120 \times 15 \times 5.7 \mathrm{~mm}^{3}\right)$. The fiber orientation for each face sheet was $[0 / 90]_{S}$. The material combinations of the D-SCM sandwich structures shown in Table 1 were tested.

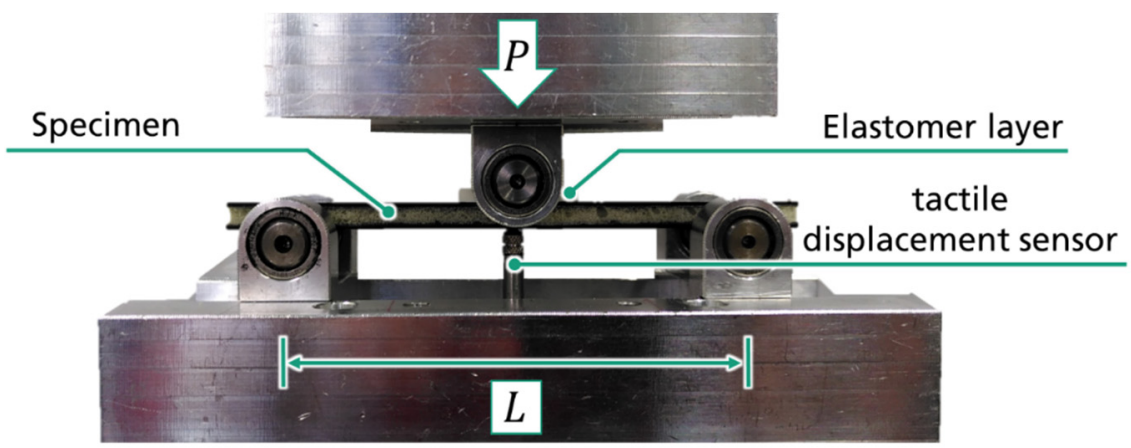

Figure 3. Three-point bending setup for sandwich characterization.

A $2.5 \mathrm{kN}$ load cell records the test force required to deflect the specimen. The corresponding specimen deflection was recorded via a tactile displacement sensor centered underneath the specimen. To prevent settling effects, a preload of $10 \mathrm{~N}$ was applied before starting the test. The bending specimens were tested at a support span length (L) of $105 \mathrm{~mm}$ and at a test speed of $1 \mathrm{~mm} / \mathrm{min}$ until failure. The test ended at a force reduction of $20 \%$ to the measured maximum force (force cut-off threshold). Three specimens of each configuration were tested.

The maximum shear stress $\tau_{\max }$ corresponds to the stress state at the maximum test load $P_{\text {max }}$. Formula (2) describes the general calculation basis to determine $\tau_{\text {max }}$. Since the evaluation according to the ASTM C393/C393M-16 standard only allows shear failure and 
such failure behavior can be observed in all specimens, the maximum core shear stress is equivalent to the core shear strength for the sandwich composite under consideration of a 3-point bending load.

$$
\tau=\frac{d M}{d x} \frac{1}{b \cdot c}=\frac{P}{b \cdot c}
$$

with $M=$ bending moment, $b=$ specimen width,

$c=$ combined thickness of core and one face sheet

The bending stiffness $D_{S}$ and the shear stiffness $G_{C}$ can be determined by considering the compliance $C=\delta / P(\delta=$ displacement $)$ and the correlation in Formula (3) [27]:

$$
C=\frac{L^{3}}{48 \cdot b \cdot D_{S}}+\frac{L}{4 \cdot t_{C} \cdot b \cdot G_{C}}
$$

$$
\text { with } L=\text { support distance, } t_{C}=\text { core thickness }
$$

Due to the valid assumption of significantly stiffer and relatively thin face sheets compared to the core, the bending stiffness $D_{S}$ was reduced to the bending stiffness $D_{0}$ of the face sheets respective to the centroidal axis of the entire sandwich cross section and can be determined directly using the face sheet stiffness $E_{F S}$ measured in the tensile tests by applying Formula (4). The core shear stiffness $G_{C}$ can then be derived by inserting the calculated bending stiffness $D_{S}$ into Formula (3).

$$
D_{S}=D_{0}=\frac{E_{D} * b * c^{2} * t_{D}}{2}
$$

\section{Results}

\subsection{The D-SCM Manufacturing Process}

It is possible to manufacture sandwich structures (shown in Figure 4) using the DSCM process strategy. All samples listed in Table 1 can be produced and result in testable components. The surface qualities indicate a good fiber impregnation in the face sheets. Starting from a centered resin application, the fiber reinforcement in the face sheets is impregnated by the fluid flow, induced through the PUR foaming pressure.

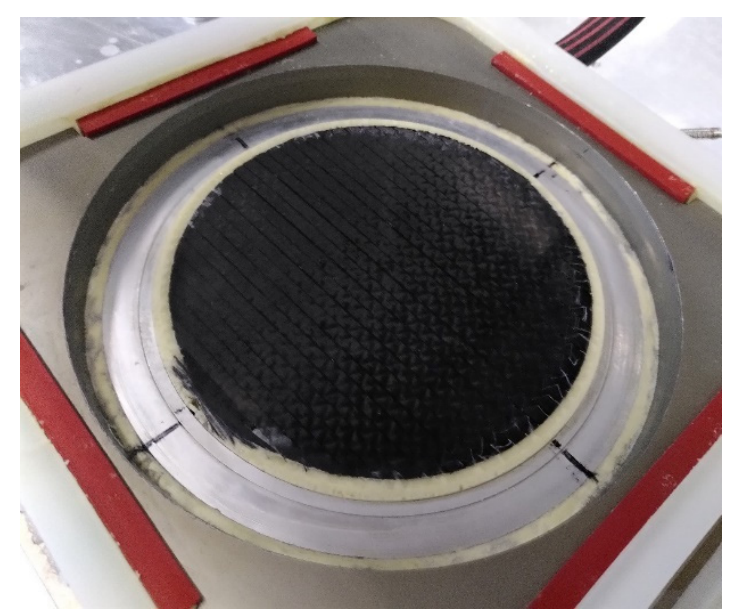

(a)

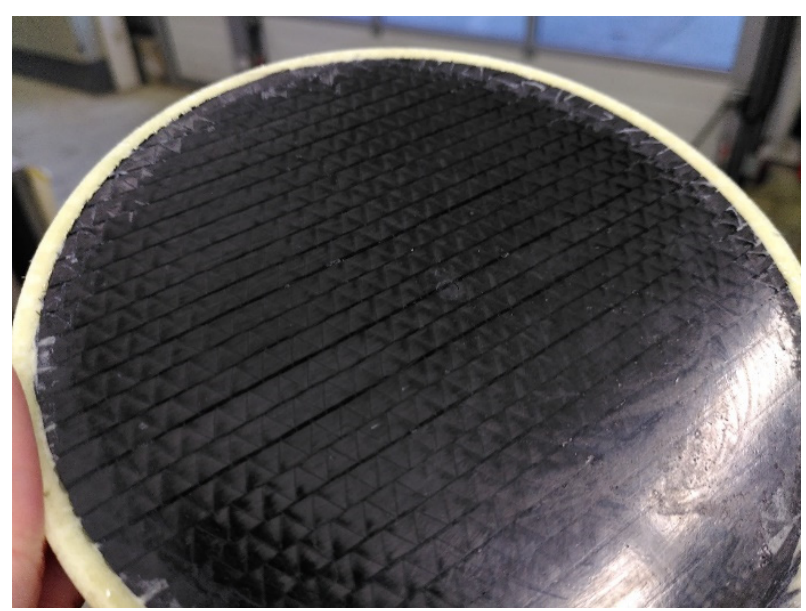

(b)

Figure 4. D-SCM sandwich structures: in the lower cavity after mold opening (a); demolded, cured sandwich component $(\mathbf{b})$.

\subsection{Fiber Volume Content of the Face Sheets}

Figure 5 shows the determined FVC in the face sheets for the D-SCM sandwich structures, according to the foam core density and the resin system. For both resin systems, the average fiber volume contents range between 30 and $35 \%$ and thus are at similar levels. 


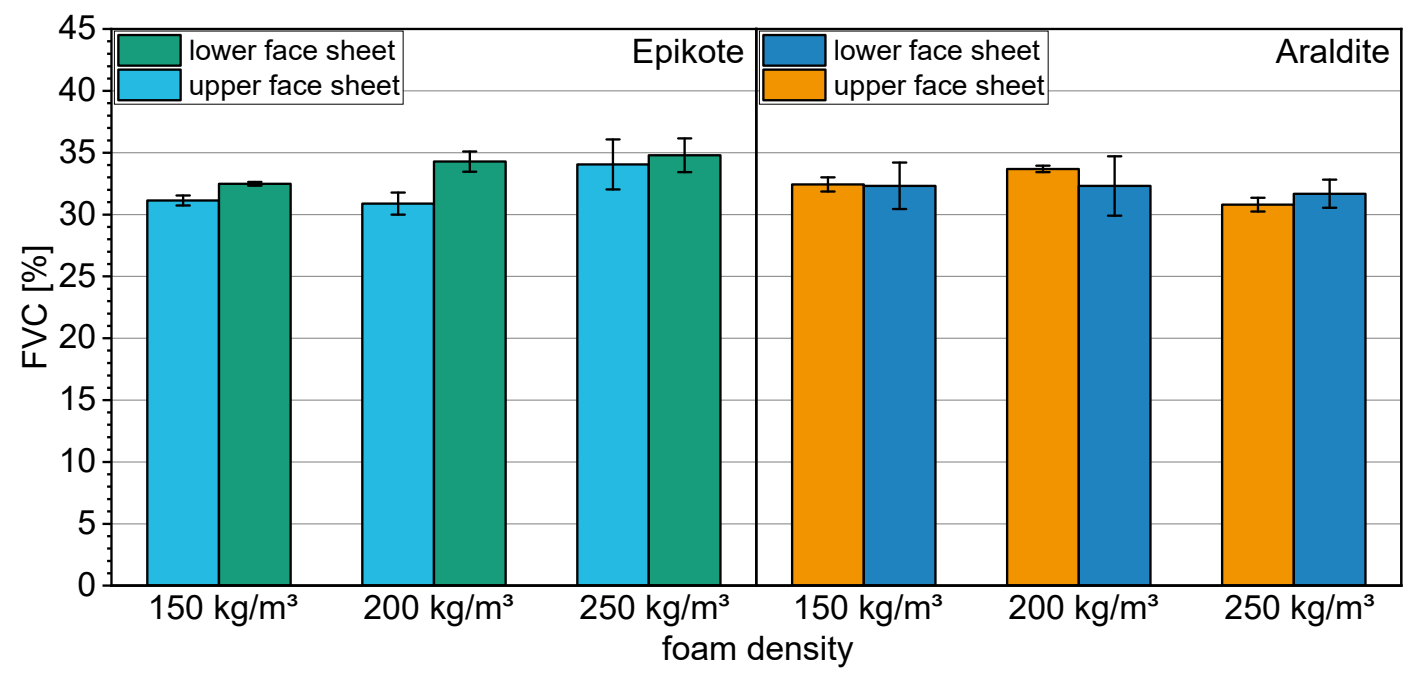

Figure 5. Fiber volume contents of the lower and upper face sheets according to the foam core density for the Epikote (left) and the Araldite resin systems (right).

For the Epikote resin system, the lower face sheet had a higher average FVC than the upper face sheet. This is due to the fact that the lower face sheet was inserted into the mold first and warmed up. As a result, the viscosity of the resin initially decreased due to the temperature, and the resin system could already start to flow over the surface and impregnate the fibers due to weight and capillary forces. Due to the comparatively slow reaction rate of the Epikote system, the material in both face sheets was still flowable at the time of the PUR pressure build-up in the closed mold; however, the flow front had already more progressed in the lower face sheet due to the above-mentioned temperature effect. The mean FVC increased with increasing foam density. The increasing foam density leads to a higher foam pressure and consequently to a higher fluid pressure in the face sheets. This allows the flow front to impregnate the dry fiber reinforcement further in the face sheet, resulting in higher FVC.

However, for the Araldite resin system, no such significant trend with respect to the FVC in the face sheets can be identified. The standard deviations for the upper and the lower face sheets always overlap and also do not show an analogous behavior like they do for the Epikote specimens. The Araldite system is more challenging to be processed in the manual procedure due to its significantly higher reactivity. In case of small time differences in the individual process steps during the manual specimen manufacturing, viscosity increases can occur during processing. This limits the flowability and no clear trend of the FVC can be identified with respect to the increasing foam density.

\subsection{Stiffness of the Face Sheets}

The results for the face sheets stiffness $E_{F S}$ determined in the tensile test relating to the foam density are shown in Figure 6. In addition, the bending stiffness $D_{S}$ determined on the basis of the face sheet stiffness using Formula (4) is also illustrated.

The face sheet stiffness determined in the tensile test are at similar levels between 40.4 and $45.4 \mathrm{GPa}$ for all specimens tested. For both investigated resin systems, a moderate increase in the average stiffness with increasing foam density can be identified. This can be explained by the also slightly increasing FVC in the face sheets (shown in Section 4.2). However, the overlapping standard deviations do not indicate any significant effect. With regard to the values of the bending stiffness $D_{S}$, an analogous trend of the mean values can be observed. Since the face sheet reinforcement as well as the FVC do not change significantly, the results of the tensile tests are plausible. 


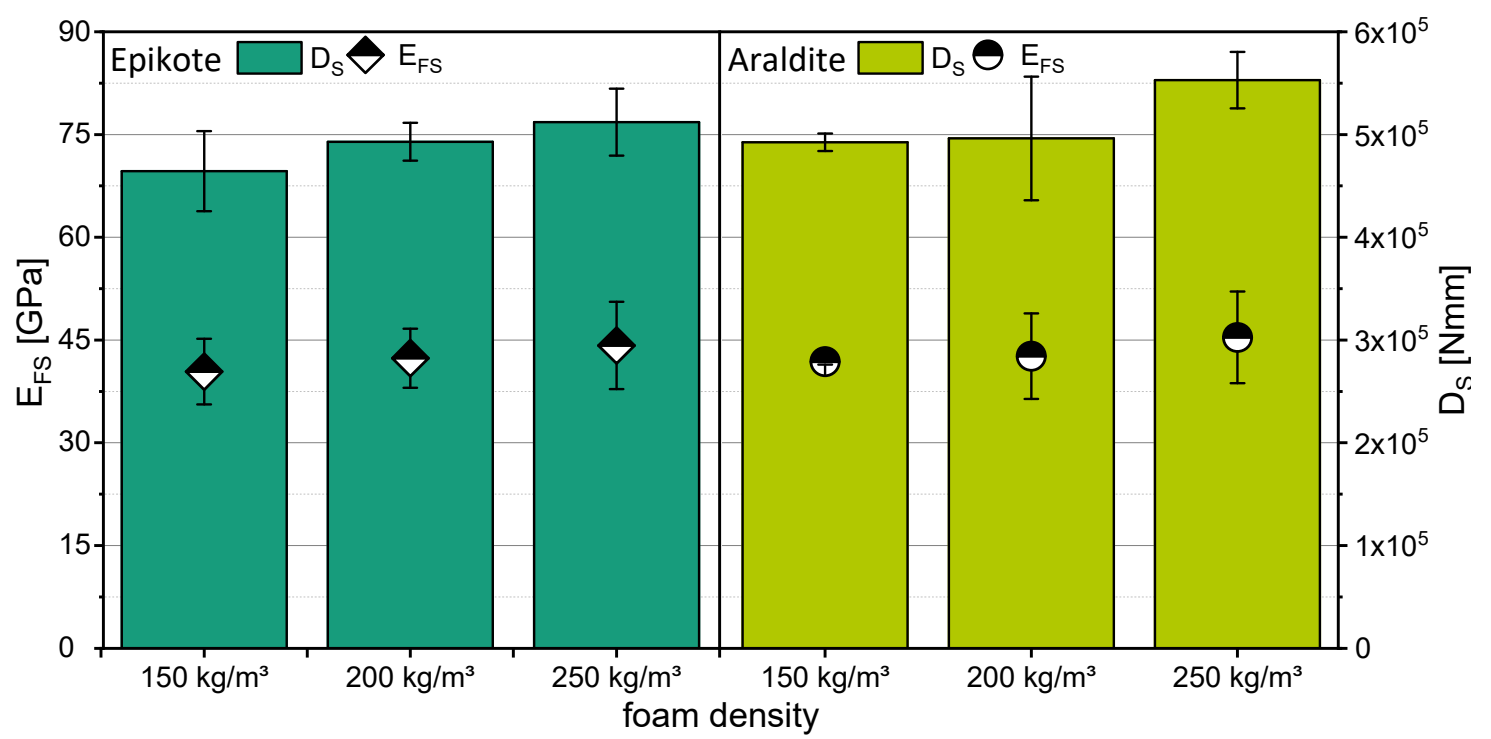

Figure 6. Face sheet stiffness, determined in tensile tests $E_{F S}$ (dot plot) and the resulting bending stiffness $D_{S}$ (bar graph) for the Epikote (left) and the Araldite (right) resin systems.

\subsection{Three-Point Bending Behavior of the D-SCM Sandwich Structures}

The specimen failure is comparable in all tests performed. A face sheet-parallel crack propagation in the foam structure on the specimen compression side near the face sheet/core interface occurred in the longitudinal specimen direction. The failure pattern resembles a classic delamination. However, the TPU interface is not the weak component of the sandwich structure. In all specimens, a continuous layer of foam residue remains adhered to the TPU film (shown in Figure 7). Consequently, the foam structure near the interface is the weak point (cohesive failure) of the composite.

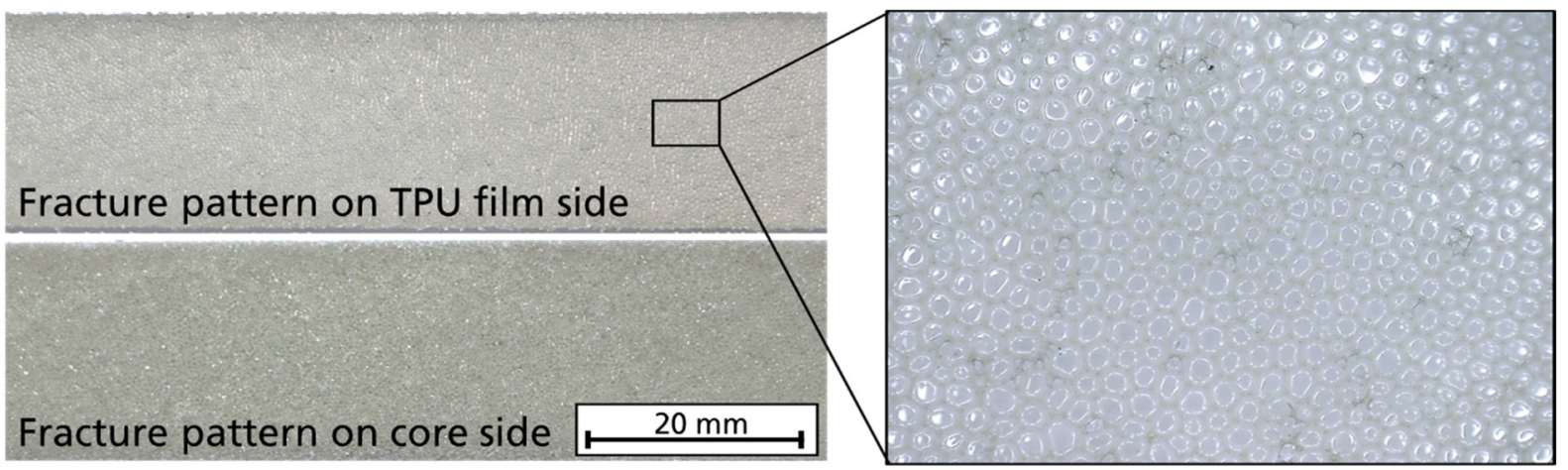

Figure 7. Fracture pattern of the cohesive failure of 3-point bending specimens.

The calculated maximum core shear strengths according to Formula (2) of the tested sandwich specimens are shown in Figure 8. 


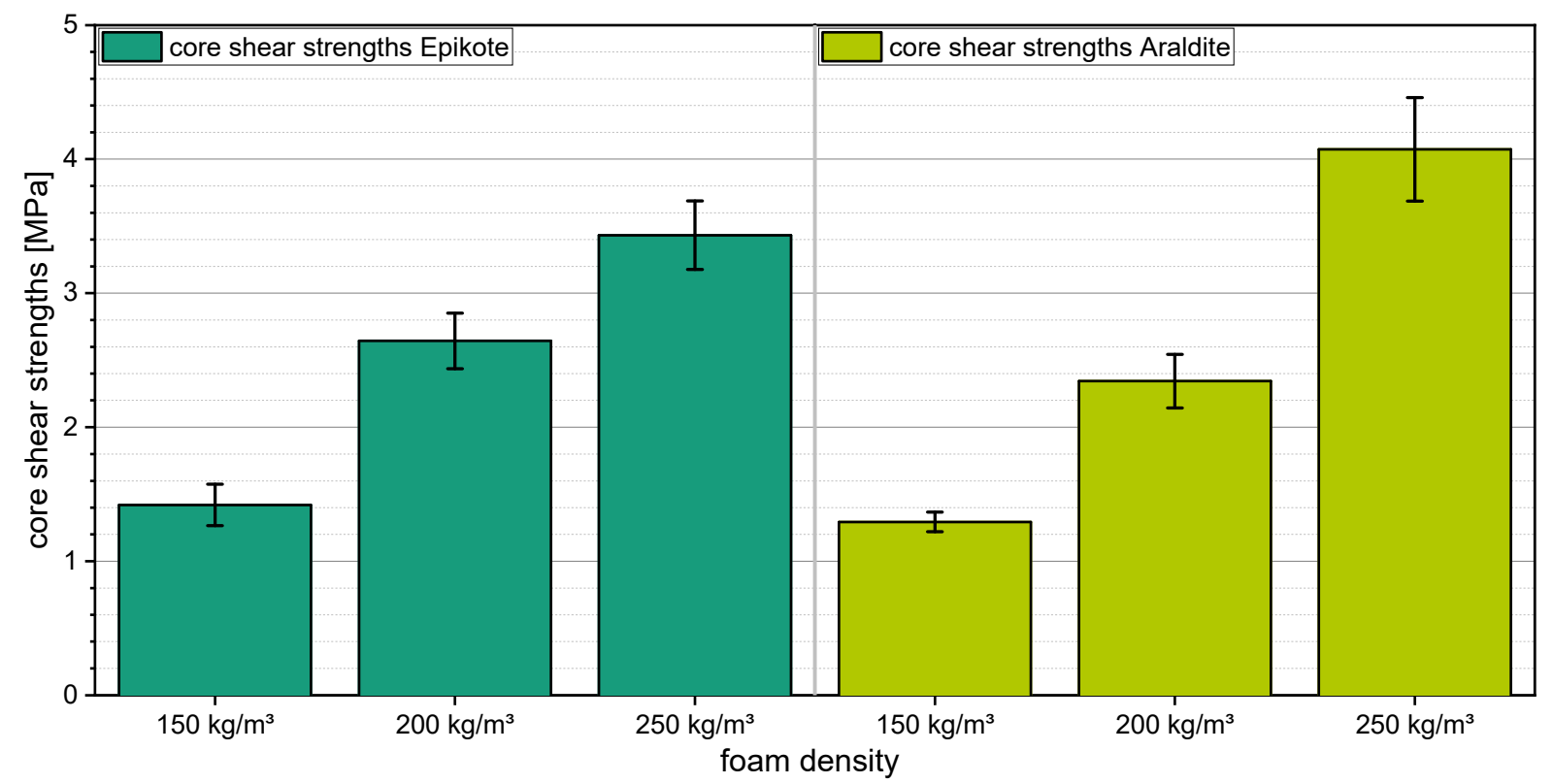

Figure 8. Core shear strength of the sandwich structures for the Epikote resin system (left) and the Araldite resin system (right).

For the specimens of the Epikote resin system in the face sheets, the core shear strength increased with the foam density from $1.4 \mathrm{MPa}$ at a density of $150 \mathrm{~kg} / \mathrm{m}^{3}$ to $3.4 \mathrm{MPa}$ for a density of $250 \mathrm{~kg} / \mathrm{m}^{3}$, representing an increase of $143 \%$. For the Araldite system, these values evolved from $1.3 \mathrm{MPa}$ at a density of $150 \mathrm{~kg} / \mathrm{m}^{3}$ to $4.1 \mathrm{MPa}$ at a density of $250 \mathrm{~kg} / \mathrm{m}^{3}$, which corresponds to an increase of $215 \%$. The determined values are compared to commercially available PUR foam core materials (e.g., LEOcore ${ }^{\circledR}: 1.2 \mathrm{MPa}$ at $145 \mathrm{~kg} / \mathrm{m}^{3}$ density [28]). The results for the determined core shear moduli $G_{C}$ by applying Formula (3), considering the bending face sheet stiffness $D_{S}$ are given in Figure 9.

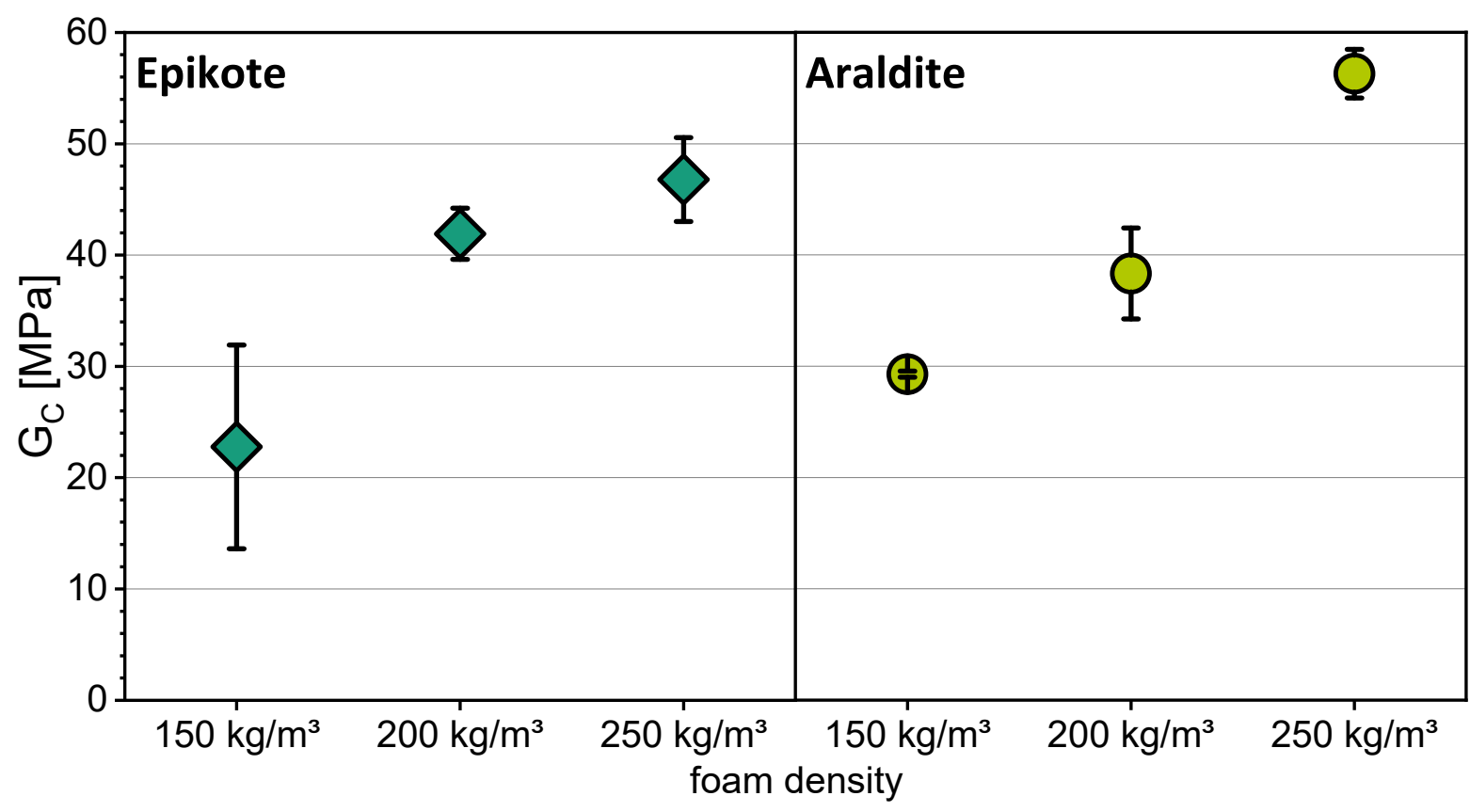

Figure 9. Core shear stiffness of the sandwich structures for the Epikote resin system (left) and the Araldite resin system (right). 
For a $150 \mathrm{~kg} / \mathrm{m}^{3}$ foam density, an average shear stiffness between 22.8 (Epikote) and $29.3 \mathrm{MPa}$ (Araldite) was found. At $250 \mathrm{~kg} / \mathrm{m}^{3}$ density, the stiffness was increased by $105 \%$ to 46.8 for Epikote, and by $92 \%$ to $56.3 \mathrm{MPa}$ for the Araldite system. The core shear modulus increased with foam density for both resin systems. For the Araldite system in the face sheets, this effect is even statistically significant as the standard deviations do not overlap.

In addition, Figure 10 shows that the foam morphology also becomes more homogeneous with increasing density and includes less instabilities. The resulting increase in foam quality also leads to a higher load-bearing capacity of the core structure.
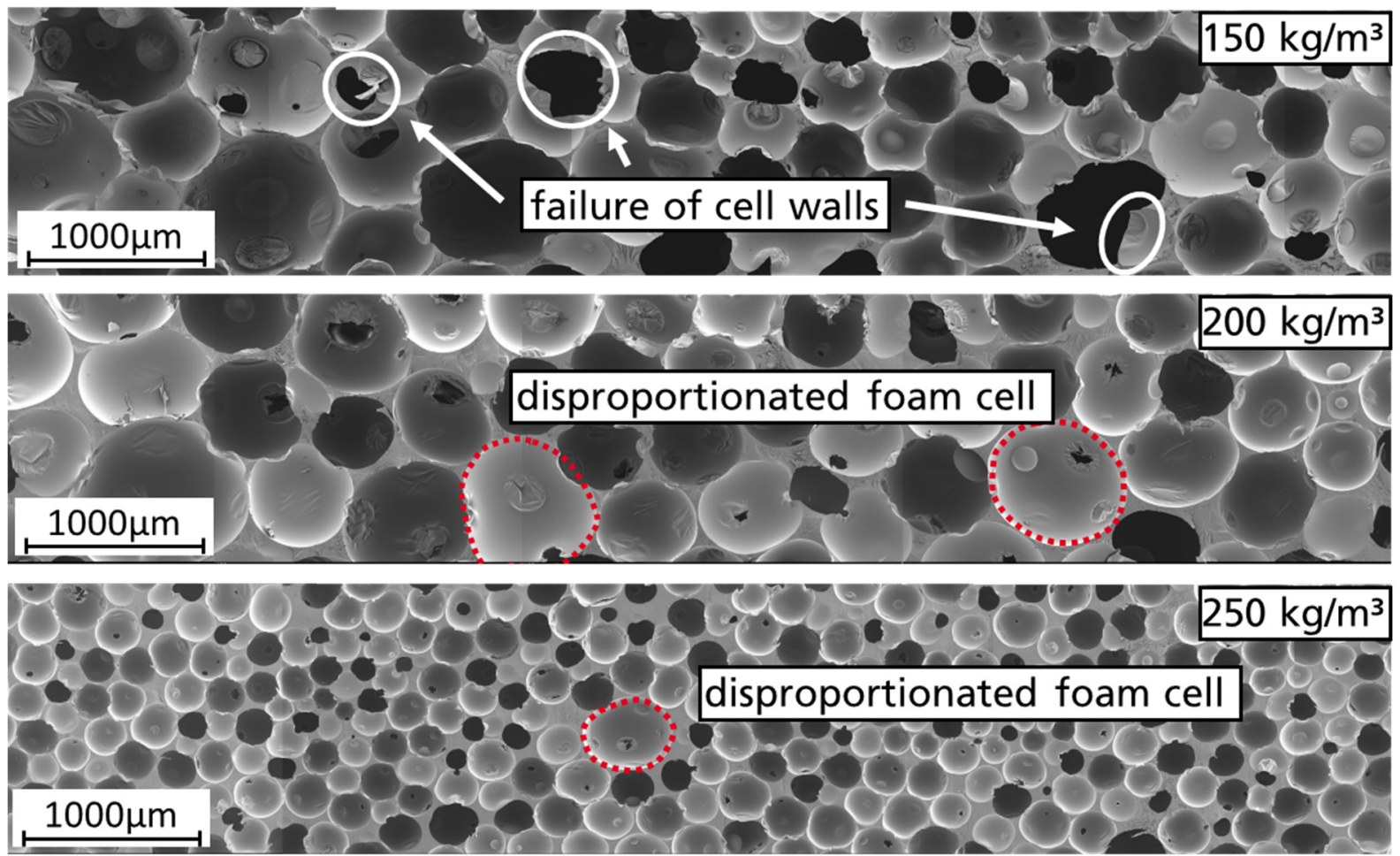

Figure 10. PUR foam morphology at $150 \mathrm{~kg} / \mathrm{m}^{3}$ (top), $200 \mathrm{~kg} / \mathrm{m}^{3}$ (middle) and $250 \mathrm{~kg} / \mathrm{m}^{3}$ (bottom) foam density.

Disproportionations of the foam cells occur due to the higher pressure in smaller pores during the gas bubble growing phase of the chemical foaming process. In this process, the generated $\mathrm{CO}_{2}$ diffuses from small to larger cells to compensate for the local pressure difference [29,30]. Consequently, irregular cell sizes and open cell structures occur. Such foaming behavior is disadvantageous, since it impairs the mechanical properties of the foam structure.

This effect is further enhanced by the adapted foam system for the D-SCM process and the resulting higher pressure level. The comparatively low polymer mass at $150 \mathrm{~kg} / \mathrm{m}^{3}$ foam density is not able to sufficiently stabilize the cell walls during the foam formation.

The foam structure at $200 \mathrm{~kg} / \mathrm{m}^{3}$ foam density still shows instabilities. However, in contrast to the structures obtained at a density of $150 \mathrm{~kg} / \mathrm{m}^{3}$, these instabilities are much less pronounced. The cell sizes at 150 and $200 \mathrm{~kg} / \mathrm{m}^{3}$ foam density are comparable. Even at an increased density, disproportionation effects still seem to occur, preventing a highly distributed structure of small cells. The improved foam quality is due to the supporting effect of the increasing polymeric PUR material at a density of $200 \mathrm{~kg} / \mathrm{m}^{3}$. Although the process pressure increases with the increasing foam density, the polymer mass is able to stabilize the cell structure to a large extent and prevent open-celling. Thus, useful for their mechanical stablility, foam structures can be generated at higher process pressures.

Figure 10 (bottom) shows a representative section of a foam structure with a $250 \mathrm{~kg} / \mathrm{m}^{3}$ foam density. The cells are closed without exception and the distribution is largely homo- 
geneous. The cell size is significantly smaller compared to the 150 and $200 \mathrm{~kg} / \mathrm{m}^{3}$ foam densities. Local disproportionation effects lead very occasionally to larger foam pores. In contrast to the foam structures for the 150 and $200 \mathrm{~kg} / \mathrm{m}^{3}$ foam densities, the increased PUR mass for the $250 \mathrm{~kg} / \mathrm{m}^{3}$ foam density is able to stabilize the cell walls during the entire foaming process. Due to the increased density, the D-SCM process pressure for a density of $250 \mathrm{~kg} / \mathrm{m}^{3}$ is increased. However, the cell morphology shows that this effect has no negative influence on the chemical foaming process.

\section{Discussion}

The determined fiber volume contents for the face sheets of the D-SCM sandwich structures are all within a range between 30 and $35 \%$ and thus below the target values of $44.2 \%$. Comparable two-step process variants such as RTM in combination with a foam core allow FVC between 50 and $60 \%$. For the investigated process window between 150 and $250 \mathrm{~kg} / \mathrm{m}^{3}$ foam density, the expected increase in the FVC with rising foam pressure has not been identified for the Araldite system in the face sheets. For the Epikote resin system in the face sheets, a slight increase in the FVC mean values can be observed. This is due to the characteristics of the D-SCM process, in that the foam pressure acts simultaneously on the dry textile and on the applied fluid. This results in a necessary resin flow through the dry textile in the non-impregnated areas, which are already compacted by the foam pressure. This compaction of the dry fabric areas leads to a decreased permeability and thus a higher flow resistance. As a result, the fluid flow in the face sheets is impeded. The higher the foam pressure, the higher the compaction of the dry areas and thus the flow resistance. This effect partially offsets the increased fluid pressure due to the higher foam pressure.

Following the relatively constant fiber volume content, the stiffness of the face sheets and the corresponding bending stiffness do not change significantly by increasing the foam density. This behavior is plausible due to the constant face sheet reinforcement.

The core shear properties influence the sandwich behavior under a three-point bending load significantly. Due to the increased amount of polymer material, the load-bearing capacity of the foam core is increased at higher densities. As solely shear failure in the foam core was observed during the three-point bending tests, the shear strength of the core is the failure-relevant parameter. An increased shear strength leads directly to an increase in the sandwich structure performance under bending load. Analogically to the shear strength, the shear modulus also increases as a result of the increased amount of polymer material in the core with higher foam densities. In general, the determined shear strengths $\left(150 \mathrm{~kg} / \mathrm{m}^{3}\right.$ density: 1.4 MPa for Epikote, 1.3 MPa for Araldite) are within a plausible range of values, since literature values of comparable rigid PUR foams are in the same order of magnitude (e.g., LEOcore ${ }^{\circledR}$ with $145 \mathrm{~kg} / \mathrm{m}^{3}$ foam density and $1.2 \mathrm{MPa}$ shear strength [28]).

In addition to the foaming pressure [18], the foam morphology is also influenced by the PUR foam density. During the chemical foaming process, the cell structure must be stabilized by a sufficient amount of polymeric PUR material. However, an increasing foam density results in a higher component weight and must therefore be optimized on the application requirements. The increasing core shear properties with an increasing density represent a combined effect of a higher polymer mass and a more homogeneous foam structure.

The TPU film as an impermeable layer prevents foam penetration into the face sheets. The adhesion of both reactive systems (resin and foam) does not represent an explicit weak point of the sandwich structure. The TPU film thus fulfills its intended purpose in the D-SCM process. For a large-area and complex geometries, integration of the film within the process chain may be challenging. The TPU material used in this work has only limited stretchability, which makes it difficult to drape double-curved areas. For such an application, the film must be replaced by a more stretchable material. 


\section{Conclusions}

The infiltration of the face sheets is possible with both resin systems investigated. The potentially time-critical processing with the more reactive Araldite system is not confirmed. For the relevant process steps, the viscosity ranges of both resin systems are not critical. The D-SCM process can be used for the one-step manufacturing of sandwich structures.

The processing conditions and the resulting structural properties of the sandwich components can be mainly controlled by the foam density when considering a constant fiber reinforcement structure in the face sheets.

In principle, the substitution of individual materials for the production of sandwich structures in the D-SCM process is possible. The required basic knowledge for the material substitution was determined within the investigations. In the case of material substitution, the effects of the changing, time- and temperature-dependent properties of the reactive components must be considered in the context of the overall process strategy. The face sheet resin system must have sufficient flowability corresponding to the pressure build-up time of the foam. For the TPU film as well as the fiber structure, basic compatibility with the reactive systems involved is essential. In addition, the necessary flexibility for molding the required part geometry must be ensured.

Author Contributions: Conceptualization, F.B. and H.O.W.; methodology, F.B., J.B. and H.O.W. validation, F.B., J.B. and H.O.W.; formal analysis, F.B., J.B. and H.O.W.; investigation, F.B., J.B. and H.O.W.; resources, F.B., J.B. and H.O.W.; data curation, F.B., J.B. and H.O.W.; writing-original draft preparation, F.B.; writing-review and editing, H.O.W., J.B. and F.H.; visualization, F.B.; supervision, F.H.; project administration, F.B. and H.O.W.; funding acquisition, F.B. and F.H. All authors have read and agreed to the published version of the manuscript.

Funding: Financial support by the project Profilregion Mobilitätssysteme Karlsruhe is gratefully acknowledged. In the state of Baden-Württemberg, the Profilregion Mobilitätssysteme is funded equally by the Ministry for Economy, Labor and Housing, the Ministry of Science, Research and the Arts as well as through contributions from the Fraunhofer Society, the Karlsruhe University of Applied Sciences (HsKA) and the Karlsruhe Institute of Technology (KIT). Furthermore, the Profilregion Mobilitätssysteme Karlsruhe is supported by the strategic industry partner Hengrui Group which is greatly appreciated.

Informed Consent Statement: Not applicable.

Data Availability Statement: Not applicable.

Acknowledgments: The authors would like to thank their colleagues from Fraunhofer ICT, Pfinztal: Cahit Arik, Markus Reeb and Christian Ress for technical and analytical support. The polyurethane foam supplier Rühl Puromer $\mathrm{GmbH}$ as well as the fiber textile supplier Zoltek Corporation and resin suppliers Huntsman Corporation and Hexion are also gratefully acknowledged for providing the materials used. Special thanks to the strategic industry partner Hengrui Group for the great support.

Conflicts of Interest: The authors declare no conflict of interest.

\section{References}

1. European Composites Industry Association. Carbon Fiber LCA Data in EcoCalculator: An Essential Extension; Composites Europe: Stuttgart, Germany, 2018.

2. Vinson, J.R. Sandwich Structures. Appl. Mech. Rev. 2001, 54, 201-214. [CrossRef]

3. Zenkert, D. An Introduction to Sandwich Structures-Student Edition; Engineering Materials Advisory Services Publishing: Birmingham, UK, 1995; ISBN 978-0947817770.

4. Zenkert, D.; Nordic Industrial Fund. The Handbook of Sandwich Construction; Engineering Materials Advisory Services Publishing: Birmingham, UK, 1997; ISBN 978-0947817961.

5. Thomsen, O.T.; Bozhevolnaya, E.; Lyckegaard, A. (Eds.) Sandwich Structures Technology in Commercial Aviation. In Sandwich Structures 7: Advancing with Sandwich Structures and Materials, Proceedings of the 7th International Conference on Sand-wich Structures, Aalborg University, Aalborg, Denmark, 29-31 August 2005; Springer: Dordrecht, The Netherlands, 2005; ISBN 978-1-4020-3444-2.

6. Gerstenkorn, J. Entwicklung einer Methodik zur Analyse und Vorhersage des Mechanischen Verhaltens Polymerer Hartschäume im RTM-Prozess. Ph.D. Thesis, Karlsruher Institute for Technology, Karlsruhe, Germany, 2021. 
7. Rosenberg, P. Entwicklung einer RTM Prozessvariante zur Kavitätsdruckgeregelten Herstellung von Faserverbundstrukturbauteilen. Ph.D. Thesis, Karlsruher Institute for Technology, Karlsruhe, Germany, 2018.

8. Seibert, H.F. Applications for PMI foams in aerospace sandwich structures. Reinf. Plast. 2006, 50, 44-48. [CrossRef]

9. Ware, M. Thermal Expansion Resin Transfer Molding (TERTM)—A Manufacturing Process for RP Sandwich Core Structures. In Proceedings of the 40th Annual Conference, Atlanta, GA, USA, 28 January-1 February 1985; Reinforced Plastics/Composite Institute: New York, NY, USA; The Society of Plastic Industry, Inc.: New York, NY, USA, 1985.

10. Ware, M. Thermal Expansion Resin Transfer Molding(TERTM)_An Advanced Composite Mass Production Process. In Society of Manufacturing Engineers, Proceedings of the 5th Conference on Composites in Manufacturing, Los Angeles, CA, USA, 13-16 January 1986; Society of Manufacturing Engineers: Southfield, MI, USA.

11. Burr, S.T.; Tudor, J.M.; Athreya, S.R.; Parsons, T.J. Expanding Foam Core Prepreg. PCT/US2013/070033, 14 November 2013.

12. Beukers, A. A new technology for sandwich plates and structures based on the use of in-situ foamable thermoplastic films. In Proceedings of the 37th International SAMPE Symposium and Exhibition, Anaheim, CA, USA, 9-12 March 1992 ; pp. $172-185$.

13. Hopmann, C.; Karatzias, C.; Böttcher, A. Syntaktische Schäume zur einstufigen Sandwichherstellung von FVK. Lightweight Des. 2016, 9, 44-51. [CrossRef]

14. Weißenborn, O. Entwicklung eines Neuartigen Imprägnierschäumverfahrens zur Herstellung Komplex Geformter PolyurethanSandwichverbundstrukturen. Ph.D. Thesis, Technische Universität Dresden, Dresden, Germany, 2020.

15. Weißenborn, O.; Geller, S.; Jaschinski, J.; Gude, M. Modelling the bending behaviour of novel fibre-reinforced sandwich structures with polyurethane foam core. IOP Conf. Ser. Mater. Sci. Eng. 2018, 416, 012073. [CrossRef]

16. Hopmann, C.; Wagner, R.; Fischer, K.; Böttcher, A. One Step Production of High-performance Sandwich Components. Cell. Polym. 2018, 36, 135-150. [CrossRef]

17. Hopmann, C.; Riedel, R.; Karatzias, C. Strukturelle Sandwichbauteile mit prozessintegriert ausgeschäumtem Schaumkern. Fachmag. Für Die Polyurethanindustrie 2015, 91, 11-12.

18. Behnisch, F.; Lichtner, V.; Henning, F.; Rosenberg, P. Development of a Reactive Polyurethane Foam System for the Direct Sandwich Composite Molding (D-SCM) Process. J. Compos. Sci. 2021, 5, 104. [CrossRef]

19. ZOLTEK Corporation (Toray Group). ZOLTEK ${ }^{\mathrm{TM}}$ PX35 Multi-Directional Fabrics; Technical Datasheet; ZOLTEK Corporation (Toray Group): Bridgeton, MO, USA, 2021.

20. Hexion ${ }^{\mathrm{TM}}$ Inc. Datenblatt EPIKOTE ${ }^{\mathrm{TM}}$ Resin Trac 06170; Hexion Inc.: Columbus, OH, USA, 2017.

21. Huntsman Corporation. Datenblatt Araldite ${ }^{\circledR}$ LY 3031/Aradur ${ }^{\circledR}$ 3032; Huntsman Corporation: The Woodlands, Texas, USA, 2015.

22. Rühl Puromer GmbH. Datenblatt Rühl Puromer EP 3587/2; Rühl Puromer GmbH: Friedrichsdorf, Germany, 2017.

23. Bücheler, D.; Kaiser, A.; Henning, F. Using Thermogravimetric Analysis to Determine Carbon Fiber Weight Percentage of Fiber-Reinforced Plastics. Compos. Part B Eng. 2016, 106, 218-223. [CrossRef]

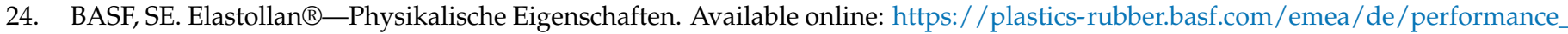
polymers / products / elastollan.html?at_medium=sl\&at_campaign=PM_BAW_EMEA_DE_Elastollan_TRA_CROSS\&at_term=

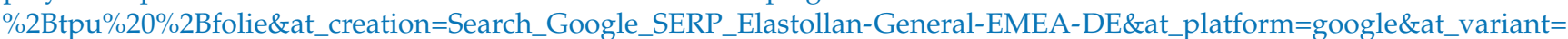
Elastollan-General-EMEA-DE (accessed on 12 December 2021).

25. Xiong, J.; Ma, L.; Wu, L.; Liu, J.; Vaziri, A. Mechanical behavior and failure of composite pyramidal truss core sandwich columns Compos. Part B Eng. 2011, 42, 938-945. [CrossRef]

26. Wesolowski, M.; Ludewicz, J.; Domski, J.; Zakrzewski, M. Shear properties evaluation of a truss core of sandwich beams. IOP Conf. Ser. Mater. Sci. Eng. 2017, 251, 012085. [CrossRef]

27. Allen, H.G. Analysis and Design of Structural Sandwich Panels: The Commonwealth and International Library: Structures and Solid Body Mechanics Division; Elsevier: Oxford, UK, 2013; ISBN 978-1483126623.

28. Gaugler \& Lutz OHG. Produktübersicht: Ihr Starker Partner für den Leicht- und Sandwichbau. June 2019. Available online: https: //www.gaugler-lutz.de/fileadmin/user_upload/Unternehmen/Produktuebersicht_LS_DE.pdf (accessed on 12 December 2021).

29. Minogue, E. An In-Situ Study of the Nucleation Process of Polyurethane Rigid Foam Formation. Ph.D. Thesis, Dublin City University, Dublin, Ireland, 2000.

30. Lander, R.; Modro, H.; Hubel, R. Influencing the Cell Structure of Flexible Polyurethane Foams by Additives. In Proceedings of the 2014 Polyurethane Technical Conference, Dallas, TX, USA, 22-24 September 2014; pp. 22-24. 